\title{
Psicologia e Educação: repercussões no trabalho educativo
}

\author{
Karla Paulino Tonus \\ Universidade Nove de Julho - SP
}

\begin{abstract}
Resumo
Este trabalho resultou de indagações a respeito da contribuição da Psicologia da Educação para o trabalho educativo. Entende-se que um dos modos de efetivar tal contribuição é a inserção da disciplina Psicologia da Educação na grade curricular dos cursos de formação de professores. Neste artigo defende-se que o ensino de Psicologia se desenvolva numa perspectiva crítica, em que o homem seja concebido como constituído historicamente. A ênfase nesta perspectiva deveu-se à análise da literatura que oferece embasamento teórico às práticas educativas orientadas pela Psicologia da Educação. O objetivo é oferecer elementos para se pensar uma educação dirigida ao homem concreto como uma das contribuições que a Psicologia pode oferecer a um trabalho educativo comprometido com a superação do subjetivismo.
\end{abstract}

Palavras chave: Formação de professores, educação, psicologia da educação.

\section{Psychology and Education: repercussions on educational work}

\begin{abstract}
This work is the result of an investigation concerning the educational psychology's contribution to educational work. We understand that one means of such contribution is through the subject "educational psychology" in teacher's professional courses. We argue that the psychology teaching is materialized by means of a critical perspective, in which one presents man as historically constituted. The focus on this perspective proceeds from an analysis about the basis that offers a theoretical approach to the educational praxis oriented by educational psychology. We propose to offer elements to think about a guided education to a concrete man. We believe that this is one of the contributions that the psychology can offer to educational work committed to overcoming in a subjectivism.
\end{abstract}

Key words: Teacher education, educational psychology.

\section{Psicología y Educación: repercusiones en el trabajo educativo}

\section{Resumen}

Este trabajo es resultado de indagaciones sobre la contribución de la psicología de la educación al trabajo educativo. Se entiende que una de las formas de realizar tal contribución es a través de la disciplina "psicología de la educación" en cursos de formación de profesores. En este artículo se defiende que la enseñanza de psicología sea objetivada por una perspectiva crítica, que presenta la concepción de hombre históricamente constituido. El énfasis en esta perspectiva procede del análisis de la literatura acerca de los fundamentos que ofrecen base teórica a las prácticas educativas orientadas por la psicología de la educación. El objetivo es aportar elementos para pensar en la educación dirigida al hombre concreto como una de las contribuciones que la psicología puede ofrecer al trabajo educativo comprometido con la superación del subjetivismo.

Palabras clave: Formación de profesores, educación, psicología educacional. 


\section{Introdução}

A nossa experiência na docência da disciplina Psicologia e Educação ${ }^{1}$ nos cursos superiores de formação de professores, especialmente no de Pedagogia, tem nos levado a refletir sobre a relevância, para a construção do trabalho educativo, dos conhecimentos acumulados pela psicologia da educação. Principalmente, tem nos provocado a indagar se o aluno do curso de Pedagogia, futuro professor, compreende a importância desta disciplina para a sua formação e, sobretudo, como ela poderá realmente colaborar em sua atividade docente, em termos de qualidade e coerência teórico-metodológica.

A não apropriação ${ }^{2}$, pelos professores em formação, das teorias psicológicas apresentadas nos cursos de formação de professores é um dos fatos que nos levam a questionar o objetivo da disciplina Psicologia e Educação nos referidos cursos, pois entendemos que tal objetivo precisa ser revisto e direcionado para a efetiva construção do trabalho educativo numa perspectiva crítica, uma vez que, de outro modo, só serviria para "psicologizar" problemas dos alunos.

Afirmamos que a não apropriação das teorias apresentadas na disciplina Psicologia e Educação, constituinte da grade curricular dos cursos de formação de professores (com especial destaque para o de Pedagogia) é um fato que constatamos quando realizamos pequenas sondagens iniciais, com vistas à estruturação desta questão ${ }^{3}$.

Com o objetivo de justificar nossa ênfase na necessidade de uma práxis educativa pela mediação dos conteúdos da disciplina Psicologia da Educação na perspectiva sócio-histórica, analisaremos neste artigo as relações estabelecidas historicamente entre a Psicologia e a Educação. Esta análise deverá ser feita com a mediação, sobretudo, da compreensão de homem presente nestas relações. A concepção de homem destaca-se como a principal categoria de análise, da qual decorrem as implicações educacionais conforme os pressupostos filosóficos que a norteiam.

Não obstante, devemos estar alerta quanto aos princípios do pensamento crítico, pelo qual pretendemos nos pautar. Neste sentido, compreender as relações entre a Psicologia e a Educação requer que olhemos para esta relação buscando enxergar além de suas aparências, visando entender aos conteúdos ideológicos presentes nas concepções historicamente elaboradas pela Psicologia da

1 Utilizaremos o termo "psicologia e educação" para nos referirmos às disciplinas que tratam da relação entre esses dois campos do conhecimento e que podem apresentar nomes distintos conforme a instituição de ensino que as trazem em sua grade curricular, ex: "Psicologia da Educação I/II", "Desenvolvimento e Aprendizagem", "Psicologia do Desenvolvimento", "Psicologia e Educação" etc.

2 Neste trabalho, a termo "apropriação das teorias" assume o significado de utilização de uma teoria como mediadora do trabalho educativo. Assume-se, ademais, a importância da existência de um único referencial teórico da psicologia na construção do trabalho do professor.

3 Devido ao limite de laudas que precisamos considerar na elaboração deste artigo, não vamos apresentar os dados de que dispomos. O leitor interessado pode consultar nossa tese de doutoramento indicada nas referências.
Educação, os quais são impostos conforme os ideais vigentes na sociedade.

A Psicologia, enquanto ciência, veio conferir à Pedagogia um status científico no final do século XIX, época em que havia se tornado independente da Filosofia ${ }^{4}$, fato possibilitado pelo início das atividades do laboratório de Leipzig na Alemanha, por Wilhelm Wundt, em 1879 (Schultz, 1975). A Psicologia passou então a utilizar-se do método experimental das ciências naturais. Nesse mesmo final de século, a Educação também buscava distanciar-se do caráter especulativo da filosofia, e a Psicologia veio a contribuir neste sentido, com pesquisas experimentais e teorias, conferindoIhe caráter científico.

O desenvolvimento da ciência psicológica é marcado por distintas maneiras nas concepções da relação homem-mundo, das categorias de sujeito e objeto. Tais concepções distinguem-se pelo fato de serem ou não críticas e históricas. Scalcon (2002) apresenta três grandes concepções no âmbito da Psicologia, as quais repercutem de maneiras específicas na educação e serão descritas adiante.

\section{Concepções teórico- metodológicas em Psicologia}

Em um primeiro momento tem-se o objetivismo, inaugurando a cientificidade no estudo da consciência (psicologia fisiológica de Fechner e Wundt) e, posteriormente, no estudo do comportamento (Titchener, Thorndike, Setchenov, Pavlov). O objetivismo cientificista encontra-se no método de investigação dos fenômenos psicológicos, entretanto, parte do pressuposto idealista de que o conhecimento é predeterminado nas estruturas internas do indivíduo, que poderia ter apenas a ideia do que seria a realidade, e não propriamente conhecer a realidade como ela é.

No rol das concepções objetivistas encontram-se, entre outras, as teorias de Galton e Binet, Dewey, Watson, Skinner (Scalcon, 2002), que exerceram forte influência na educação e, consequentemente, contribuíram para corroborar a visão de homem imposta na época (início do século $X X$ ). A autora (ibid.) esclarece a relação entre psicologia científica, psicologia escolar e classes sociais:

A partir da estruturação de uma psicologia científica, tratouse de criar instrumentos de adaptação dos indivíduos a uma nova ordem social, selecionando-os e orientando-os através do trabalho e da escola, seleção essa que passou a ser realizada com base em estudos voltados para a mensuração das faculdades mentais.

\footnotetext{
4 A necessidade de independência da Psicologia em relação à Filosofia ocorre por conta da dominação dos princípios positivistas que regulam as ciências a partir do século XIX; entretanto, como veremos ao longo de todo este trabalho, a Psicologia jamais se dissociará da Filosofia, uma vez que ambas articulam-se na compreensão a respeito da constituição humana.
} 
A maior preocupação dos psicólogos centrou-se na tarefa de construir métodos e testes capazes de classificar os indivíduos em idade escolar e pré-escolar, visando à mensuração das capacidades produtivas. Portanto, tratou-se muito mais de encontrar justificativas para a divisão social em classes, logo, para o fracasso escolar, profissional e social, mas de modo que o mito da igualdade de oportunidades fosse mantido. (p. 28-29).

A este respeito, Patto (2000, p. 58) afirma que, influenciada pelos ideais liberais propagados a partir da Revolução Francesa (1789), pela teoria da evolução natural e pelo cientificismo, a Psicologia Diferencial, a nosso ver, preocupada em estabelecer as diferenças entre pessoas de classes sociais distintas, "tornou-se especialmente apta a desempenhar seu primeiro e principal papel social: descobrir os mais e os menos aptos a trilhar a 'carreira aberta ao talento' supostamente presente na nova organização social [...]".

A segunda concepção psicológica apresentada por Scalcon (2002) no tocante à visão de homem e suas repercussões na educação denomina-se subjetivismo, que também é de origem idealista. Embora apresentadas em segundo lugar, estas posições, a partir de um determinado momento, passaram a coexistir, ou seja, passaram a apresentar-se simultaneamente. O subjetivismo tem como importante referencial a filosofia de Emanuel Kant, que propõe ser a consciência o resultado de sensações subjetivas. Esta concepção está presente nas psicologias existencial-humanista e Gestalt - principais representantes do idealismo no âmbito da Psicologia.

A concepção subjetivista, ao opor-se ao objetivismo, apresenta uma forma diferente de entender a educação e sua importância; deste modo, em oposição à escola tradicional, preocupada com o conteúdo e a rigidez moral, desenvolve-se o movimento da Escola Nova, que tem o propósito de oferecer ao aluno autodesenvolvimento, realização pessoal e liberdade numa sociedade capitalista em plena ascensão.

Segundo Scalcon (2002) (p. 32-33), tanto a Psicologia Objetivista quanto a Subjetivista, à parte as distinções na compreensão da posição do sujeito e do objeto na relação com o conhecimento, assemelham-se na concepção de que a existência seja determinada pela consciência. Podemos até mesmo afirmar que as vertentes objetivistas/cientificistas partem de uma concepção idealista, tal como as vertentes subjetivistas.

O interacionismo é, segundo Scalcon (2002), a terceira concepção psicológica que procura explicar a constituição humana e a relação entre sujeito e objeto. O interacionismo, concepção epistemológica desenvolvida por Jean Piaget, representa uma tentativa de manter o objetivismo na Psicologia com estudos científicos sobre o desenvolvimento da inteligência. A construção do conhecimento, tema central do interacionismo, depende da ação do sujeito em relação ao ambiente; sujeito e ambiente são tomados, portanto, em separado. Embora parta do princípio de que o ambiente é condição essencial ao desenvolvimento cognitivo, a ênfase é dada ao sujeito que realiza a ação de adaptar-se ao meio — inversamente à concepção de que o meio (sociedade) constitui condição para a estruturação da inteligência (consciência), uma vez que, ao apresentar condições adversas, faz com que o homem o adapte a si, às suas necessidades. A repercussão educacional do interacionismo pressupõe uma prática voltada para a descoberta, a ação, a autonomia e a transmissão de valores liberais.

Em síntese, ressalta-se que nenhuma das concepções apresentadas pela autora leva em conta a dimensão histórico-social da constituição humana e, embora aparentemente apresentem formas diferenciadas na elaboração de respostas acerca desta constituição, ao analisar suas essências verifica-se que se assemelham por representarem concepções acríticas - portanto, liberais - acerca de tal constituição.

Também no sentido de apontar o idealismo presente na Psicologia, Tuleski (2004) afirma que esta ciência surgiu em meio às contradições da sociedade burguesa, quando a burguesia deixava de ser uma classe revolucionária e se consolidava enquanto classe dominante, opondo-se à sua própria história ao deixar de participar da linha do desenvolvimento histórico. A autora (Tuleski, 2004) ressalta ainda a

[...] aparente contradição existente nas diversas correntes da psicologia burguesa entre o estabelecimento de uma linha de desenvolvimento genérica e natural para todos os indivíduos e, ao mesmo tempo, a naturalização das diferenças individuais, as quais são tratadas, ora como diferenças saudáveis e normais, que produziriam a também salutar e produtiva divisão social do trabalho, ora como diferenças patológicas e desviantes para as quais deveriam ser buscadas formas de tratamento. (Tuleskil, 2004, p. 127).

Neste sentido, concordamos com a afirmação da autora (ibid.) de que a Psicologia, já em seu nascimento, comprometida com os ideários burgueses e contrarrevolucionários, desconsidera o homem como síntese de múltiplas determinações e passível de transformações, uma vez que, ao compreender o psiquismo como categoria natural, estaria ajudando a burguesia a impedir uma nova revolução.

No texto em que discorre sobre as transformações históricas da consciência, Leontiev (s/d) afirma que a Psicologia deve considerar, sim, as particularidades do psiquismo humano, mas deve entendê-las como particularidades que dependem do caráter geral da consciência, o qual, por sua vez, é determinado pelas situações concretas da vida dos indivíduos.

No mesmo texto (Leontiev, s/d) o autor denuncia que o interesse da Psicologia em investigar as aptidões e propriedades psicológicas do homem está direcionado em sentido oposto ao processo das transformações da consciência. Neste sentido, afirma:

Por este fato, inverte todos os elementos: para ela, o determinado é o determinante, a consequência é a causa. Acaba mesmo por encontrar os motivos da atividade humana nos sentimentos subjetivos, nos sentimentos e emoções do interesse ou do desejo. Prosseguindo a sua 
análise nesta direção, acaba por encontrar a fonte destes sentimentos nas emoções e desejos inatos do homem, isto é, nas particularidades dos seus instintos. (p. 147)

De acordo com Leontiev (s/d), a Psicologia deve superar a oposição dualista entre atividade interna e atividade externa, que representa a concepção idealista que a permeia. Por outro lado, uma concepção histórica em Psicologia poderá fazer com que esta ciência não se separe dos problemas da vida, ao contrário, ajude a resolvê-los e auxilie na construção da vida do homem livre.

Encontramos esta mesma proposição no texto em que Bock (2000) expõe partes de sua tese de doutorado, na qual pesquisou o significado atribuído pelos psicólogos ao fenômeno psicológico. A naturalização do fenômeno psicológico representa, para a autora, um dos grandes problemas da Psicologia a ser superado quando este fenômeno for compreendido a partir da perspectiva histórica.

Tomando como pressuposto o postulado marxista de que "não é a consciência que determina a vida, mas a vida que determina a consciência" (Marx \& Engels, 2002), a Psicologia Sócio-Histórica considera o conceito de condição humana, ao invés de natureza humana, que parte do princípio da existência, a priori, de uma essência universal.

Conforme a autora, por considerar a condição humana, a Psicologia Sócio-Histórica - que entendemos ser a concepção teórica que busca a superação das limitações apresentadas pelas psicologias objetivista, subjetivista e interacionista -, concebe o homem como ser em constante movimento que transforma sua realidade ao longo do tempo e é também por ela transformado. Para autora, a condição humana representa o fato de que as formas de satisfação das necessidades humanas são construídas junto com outros homens. Assim sendo, a concepção de natureza humana não ajuda em nada, uma vez que empobrece a compreensão a respeito do homem e de seu desenvolvimento. O Barão de Munchhausen, personagem de histórias infantis alemãs, é tomado, a exemplo do que faz M. Löwy, (citado por Bock, 2000), como a expressão das ideias liberais, uma vez que transmite a ideologia da autonomia individual, da independência do homem em relação à realidade social, da autodeterminação, etc.

O individualismo, o principal conceito do liberalismo, é uma noção que foi naturalizada. A noção de indivíduo está relacionada à ascensão da burguesia e das revoluções burguesas, que acabaram por favorecer o capitalismo, em que, supostamente, o homem é livre para produzir e consumir. Ao longo do tempo o individualismo torna-se um valor central e mesmo uma referência para as produções científicas e culturais. Na visão liberal de homem, o psiquismo é compreendido de maneira abstrata e naturalizante, ao passo que, na visão sócio-histórica, os elementos do psiquismo são forjados nas relações com o mundo físico e social.

Bock (2000) esclarece que a figura do Barão de Munchhausen inspirou as concepções da Psicologia da Educação, as podem se identificar com as já citadas neste texto: o objetivismo cientificista, o subjetivismo e o interacionismo.
Tais concepções acarretam consequências ${ }^{5}$ para os alunos para a educação e para a própria sociedade, consequências que a Psicologia tem ajudado a legitimar. Para que a figura do Barão de Munchhausen deixe de inspirar teorias e práticas na Psicologia da Educação, é preciso rejeitar a naturalização do fenômeno psíquico para este poder ser compreendido como instância socialmente constituída.

\section{Psicologia, formação de professores e educação escolar}

Antes de adquirir status científico e de se denominar propriamente "Psicologia", no Brasil esta área do conhecimento já se manifestava em ideias psicológicas na educação. Klein (2000) identifica a educação como o espaço em que a Psicologia se fez mais marcadamente presente em seu início no Brasil. Também Antunes (2003), ao analisar as articulações entre a Psicologia e a Educação no Brasil, verifica a inserção de ideias psicológicas na educação desde o período colonial, principalmente nas obras escritas por jesuítas. Os temas que se destacam são: aprendizagem, determinantes do desenvolvimento emocional, cognitivo, motor e sensorial infantil, utilização de prêmios e castigos, personalidade. A autora (Antunes, 2003) destaca ainda que, embora muitas dessas ideias fossem bastante originais, elas estavam articuladas aos interesses do sistema colonial, ou ainda, por outro lado, representavam o confronto com esses interesses.

No século XIX, com a instalação dos cursos superiores no Brasil, a Psicologia surge permeando as questões educacionais nas teses inaugurais dos estudantes dos cursos de medicina. Com o funcionamento das Escolas Normais, a Psicologia aparece enquanto conteúdo, principalmente no que se refere ao desenvolvimento infantil e aos processos de aprendizagem.

Segundo Antunes (2003), embora a Psicologia viesse a fazer parte da grade curricular das Escolas Normais por meio de projeto de Lei em 1892, os conteúdos referentes ao fenômeno psíquico já aparecem em outras disciplinas, especialmente na de Filosofia.

Ainda no século XIX, as preocupações com o analfabetismo, as epidemias, as condições de saneamento, a habitação e a educação solicitavam intervenções para a superação dessas condições. Fatores como o conhecimento dos fenômenos psicológicos enquanto instrumento de controle e prevenção, e a necessidade de controlar o comportamento das pessoas que, por viverem em condições desfavoráveis, poderiam organizar e compor movimentos transformadores, conferiam à Psicologia bastante relevância.

5 Práticas educativas decorrentes da concepção de que o determinante do sucesso ou fracasso escolar é o desenvolvimento natural do aluno é um exemplo de como a naturalização do fenômeno psíquico representa uma barreira ao desenvolvimento pleno mediado pela educação escolar. $\mathrm{O}$ atual fenômeno da medicalização de crianças que apresentam dificuldades escolares é um exemplo de como os argumentos recaem sobre os indivíduos e, com isso, impedem uma compreensão mais ampla, pautada na análise de vários fatores que compõem a realidade escolar. 
A Psicologia tornou-se ainda mais necessária à educação quando se iniciou o movimento da Escola Nova, época que coincide com o projeto de uma nova nação e com a necessidade de emergência de um novo homem, que fosse produtivo em suas relações de trabalho.

Com o movimento da Escola Nova a criança passa a ser vista como naturalmente boa, entretanto, passível de ser corrompida. A escola deveria manter na criança suas características positivas -como bondade, espontaneidade e pureza. Surge a necessidade de compreender e - agora também assegurar o desenvolvimento infantil, tarefa para a qual a Psicologia foi chamada.

Antes disso, no ensino tradicional a concepção de homem era a de que este possuía uma natureza corrompida, mas com elementos passíveis de serem aperfeiçoados. $\mathrm{O}$ conhecimento era o instrumento de controle, e o professor, o modelo de perfeição.

Como esclarece Patto (2000), a Psicologia do Desenvolvimento Infantil subsidiaria uma nova pedagogia, que, oposta ao modelo impositivo, privilegiaria a participação ativa do aluno no processo de ensino e aprendizagem. De acordo com a autora (Patto, 2000, p. 48) "os pedagogos liberais do início do século $X X$, estavam carregados de um humanismo ingênuo mas bem intencionado que os levava a acreditar na possibilidade de uma sociedade de classes igualitária [...]". A Escola Nova acreditava na possibilidade de promover socialmente os mais aptos, independentemente de sua classe social, conforme propunham os ideais tidos como democráticos. Isto evidencia a relevância do pensamento crítico no processo de conhecimento das teorias, já que o pensamento crítico possibilita a compreensão das abstrações presentes no fenômeno, abrindo a possibilidade de se superarem as aparências para se compreender a essência.

Nas duas concepções de educação (a tradicional e a nova) percebemos a mesma visão de homem, segundo a qual este é dotado de uma natureza humana e já nasce com as características essenciais de seu psiquismo, que se atualizarão naturalmente com o tempo. A Psicologia e a Educação tornam-se, segundo Bock (2003), "cúmplices" ao compreenderem o fenômeno humano como algo dado a despeito de qualquer condição social, ao entenderem a natureza humana como a-histórica. Esta cumplicidade reflete-se em atitudes de culpabilização do aluno por sua própria condição, o que implica a crença de que o fracasso escolar é de responsabilidade do aluno. Assim, as condições sociais e culturais são minimizadas e a educação é compreendida como fenômeno neutro e isolado do contexto. Afirma a citada autora:

A principal consequência de qualquer situação de cumplicidade é defender os interesses daquele com o qual se é cúmplice. Aqui se dá a mesma situação: os interesses das camadas dominantes ficam garantidos. [...] A educação é divulgada como processo baseado e produtor de igualdade social. [...] As desigualdades sociais são compreendidas, então, como falta de empenho ou de dedicação à educação. (Bock, 2003, p 87-88).
As Escolas Normais, conforme aponta Antunes (2003), constituíram-se como um fértil terreno para a pesquisa e o ensino em Psicologia da Educação, possibilitando inclusive o desenvolvimento da psicologia em geral, pois, muitas das modalidades de atuação em psicologia originaram-se das demandas educacionais. A pesquisa tinha como foco principal o desenvolvimento de técnicas como testes de nível mental, aptidão, vocabulário e testes pedagógicos, reflexo do objetivismo na psicologia. Antunes (2003) ressalta que já havia a tentativa de adaptação desses testes à realidade brasileira. Essas pesquisas deram origem aos vários laboratórios de psicologia que foram fundados no Brasil a partir da década de 1930.

O ensino de Psicologia da Educação abordava principalmente as questões referentes ao desenvolvimento infantil e à aprendizagem, conhecimentos importantes para elaboração de técnicas de ensino e procedimentos didáticos. Ainda hoje, nos cursos de formação de professores a Psicologia da Educação visa contribuir para o conhecimento dos processos de desenvolvimento e aprendizagem para que se possa orientar o ensino conforme as características pertinentes a essas dimensões.

A Psicologia da Educação, enquanto disciplina, vem tendo como objetivo preparar os futuros professores para compreenderem o desenvolvimento "normal" da criança e estarem atentos ao que possa ser indicativo de "desvios de comportamento". Estar atento a tais "desvios" significa apontá-los como responsáveis pelas dificuldades de aprendizagem que o aluno possa ter.

Alvite (1981) faz a crítica ao psicologismo presente na educação com o intuito de oferecer embasamento à didática do professor, numa perspectiva liberal e exclusivista; melhor dizendo, a Psicologia (entendida como explicação dos mecanismos internos ao indivíduo) explica as atitudes do professor e do aluno. Sobre isso, é oportuno citar o que a autora já denunciava e que, tantos anos depois ,mostra-se ainda mais intenso:

Vale ressaltar a necessidade de se rever os métodos de fazer psicologia e de ensiná-la. Necessário se faz, também, que se revejam as práticas pedagógicas que se originam dela e que formam técnicos manipuladores do comportamento humano, seres alienados e conformistas, adaptados a um meio ambiente onde predominam as desigualdades e as injustiças, reprodutoras da ideologia dominante. (p. 35).

Saviani (2004) distingue o aluno empírico do aluno concreto. O aspecto empírico refere-se à compreensão do indivíduo em sua aparência, conforme as características que podem ser descritas (o que ele é física e cognitivamente, seu rendimento e seu comportamento etc.); e o aspecto da concretude refere-se à compreensão do indivíduo em seu vir-a-ser, como síntese de múltiplas determinações. Nossos estudos nos permitem compreender que as teorias usualmente mais aceitas em Psicologia da Educação consideram o aluno como indivíduo empírico, dotado apenas das características imediatamente observáveis, como já pronto.

Ainda conforme os apontamentos de Antunes (2003) sobre o caminho percorrido pela Psicologia da Educação 
no Brasil, na década de 1970 começaram a surgir críticas referentes à utilização e interpretação dos testes e suas consequências para os alunos. Os resultados desses testes faziam incidir sobre o aluno a responsabilidade por seus problemas escolares, uma vez que confirmavam, cientificamente, seus déficits intelectuais. Segundo esta autora, a expressão "problemas de aprendizagem" denota que a fonte dos problemas é a criança, e que mais adequado seria dizer "problemas escolares", visto se tratar de uma condição que é determinada por vários fatores, de ordem tanto individual como escolar e social, mas que é tratada apenas como individual. Corroborando as colocações de Bock (2003), a autora aponta ainda:

As condições sociais e, sobretudo pedagógicas eram negligenciadas. As decorrências dessa prática foram nocivas para um grande contingente de crianças, condenando-as às classes especiais que, em nome de um atendimento diferenciado, acabavam por relegá-las a uma condição pedagógica paliativa, confirmando o diagnóstico realizado produzindo a deficiência mental e reproduzindo estigmas e preconceitos. (Antunes, 2003, p 164).

Facci (2004 a) afirma que grande parte dos psicólogos que atuam nas escolas orientam seus trabalhos segundo os ideários liberais, que atribui ao indivíduo as causas do sucesso e do insucesso tanto na escola quanto na sociedade. Assim, conforme a autora, "o trabalho do psicólogo na escola tem buscado a harmonia social, o ajustamento e o enquadramento dos homens às normas sociais estabelecidas" (p. 100).

Alvite (1981) compreende que a Psicologia tem sido utilizada com vistas à adaptação e integração dos indivíduos à sociedade e às instituições, tendo sido transformada, junto com a pedagogia, em instrumento de alienação. Segundo a autora, o psicologismo só será superado quando os psicólogos a assumirem como ciência concreta.

Para Bock (2003), adotar concepções que compreendam o indivíduo no seu vir-a-ser no mundo e nas relações sociais, compreender a visão política da educação e dedicar-se ao estudo dos resultados subjetivos da experiência escolar são possíveis direções para que a Psicologia rompa com a cumplicidade ideológica em favor da ideologia dominante. O rompimento com esta cumplicidade é, a nosso ver, um compromisso que a Psicologia Sócio-Histórica assume ao substituir o termo "natureza humana" por "condição humana".

Por ocasião do X Congresso Nacional de Psicologia Escolar e Educacional (CONPE), em Julho de 2011, na cidade de Maringá, PR, tivemos a oportunidade de conhecer trabalhos realizados que representam o rompimento com o que a autora (idem) denomina "cumplicidade ideológica". Tais trabalhos indicam a possibilidade de fortalecimento de uma psicologia com interfaces que favoreçam teorias e práticas críticas no âmbito escolar e educacional; contudo, nossas observações como professora e orientadora de estágio em cursos de Pedagogia nos permitem afirmar que tais teorias e práticas precisam, ainda, ser apropriadas por professores da rede regular de ensino.

\section{Considerações finais}

A Psicologia oferecida nos cursos de formação de professores perpetua uma perspectiva subjetivista, transmitindo a ideia de que no ensino básico a condição educacional do aluno é de responsabilidade dele mesmo, ${ }^{6}$ o que reflete a individualização dos problemas escolares e a desconsideração das origens sociais e históricas de sua condição.

Segundo Tanamachi e Meira (2003, p. 16-17), numa perspectiva subjetivista, a dificuldade em aprender é tida como consequência de hereditariedade, de fatores emocionais e comportamentais, orgânicos, socioculturais e maturacionais. Esta compreensão corrobora nossa concepção de que a Psicologia, em cumplicidade com a ideologia dominante, sob o paradigma subjetivista, ainda não tem dado conta de contribuir para a verdadeira emancipação humana por meio da educação escolar, o que vem reforçar nossa hipótese de que a Psicologia Sócio-Histórica pode e deve ser transmitida aos professores em formação, essencialmente por conta de sua compreensão a respeito da constituição humana.

Goulart (2001) aponta que a concepção estabelecida e aceita de que a Psicologia da Educação é uma ciência capaz de individualizar e resolver problemas escolares vem sendo historicamente construída pelo caminho percorrido pela própria Psicologia da Educação.

No Brasil este caminho tem sido marcado pelo seu compromisso com a ideologia burguesa, mediante o favorecimento dos interesses da classe dominante e a manutenção da desigualdade social presente no sistema capitalista, por meio de teorias e métodos que reforçam o individualismo, o fracasso escolar e o agrupamento conforme as capacidades intelectuais - como fazem algumas abordagens de desenvolvimento humano e os testes psicológicos utilizados na mensuração das capacidades escolares, por exemplo.

Esta ênfase nas características individuais retira da educação escolar o seu papel essencial na constituição do homem. Nossa posição é de que a Psicologia da Educação, enquanto disciplina de cursos de formação de professores, só prosseguirá no caminho da emancipação humana quando romper com a reverência à individualidade, característica própria dos ideários psicológicos e educacionais predominantes na atualidade.

Neste sentido, por enfatizar a importância da mediação social na constituição do psiquismo e o impacto da educação escolar sobre o desenvolvimento afetivo-cognitivo, que entendemos ser a Psicologia Sócio-Histórica a

6 Conforme explica Patto (2000), as explicações da Psicologia para o fracasso escolar, embora mudem a ênfase, responsabilizam as características individuais e ambientais do aluno, como, exemplo, a inteligência, as aptidões, fatores orgânicos e emocionais, dificuldades econômicas e familiares. 
concepção teórica que oferece condições para se pensar a educação escolar e o fenômeno humano como sínteses de múltiplas determinações. Os pressupostos desta teoria, ao serem fielmente transmitidos em cursos de formação de professores, poderão auxiliá-los na realização de um trabalho educativo voltado à promoção do desenvolvimento humano.

\section{Referências}

Alvite, M. M. C. (1981). Didática e Psicologia: crítica ao psicologismo na educação. São Paulo: Loyola.

Antunes, M. A. M. (2003). Psicologia e educação no Brasil: um olhar histórico-crítico. Em M. E. M. Meira, M. A. M. Antunes (Orgs.), Psicologia Escolar: teorias críticas (pp. 139-168). São Paulo: Casa do Psicólogo.

Bock, A. M. B. (2000) As influências do Barão de Munchhausen na Psicologia da Educação. Em E. R. Tanamachi, M. Proença \& M. Rocha (Orgs.), Psicologia e educação: desafios teórico-práticos. São Paulo: Casa do Psicólogo.

Bock, A. M. B. (2003). Psicologia da Educação: cumplicidade ideológica. Em M. E. M. Meira, M. A. M. Antunes (Orgs.), Psicologia Escolar: teorias críticas (pp. 70-104). São Paulo: Casa do Psicólogo.

Anais do X Congresso Nacional de Psicologia Escolar e Educacional. (2011). Maringá, PR. Recuperado: 03 nov 2012. Disponível: http://www.conpe.com.br/wp-content/uploads/2011/02/conpe_ programacao.pdf.

Facci, M. G. D. (2004) Teorias educacionais e teorias psicológicas em busca de uma Psicologia marxista da educação. Em N. Duarte (Org.), Crítica ao fetichismo da individualidade. Campinas, SP: Autores Associados.
Goulart, I. B. (2001). Psicologia da educação: fundamentos teóricopráticos, aplicações à teoria pedagógica (8a ed.). Petrópolis, RJ: Vozes.

Klein, L. R. (2000). Construtivismo piagetiano: considerações críticas à concepção de sujeito e objeto. Em N. Duarte (Org.), Sobre o construtivismo. Campinas, SP: Autores Associados.

Leontiev, A. N. (s/d). O desenvolvimento do psiquismo. São Paulo: Moraes Editora.

Marx, K., \& Engels, F. (2002). Teses sobre Feuerbach. Em K. Marx \& F. Engels, A ideologia alemã. São Paulo: Martins Fontes.

Patto, M. H. S. (2000). A produção do fracasso escolar - histórias de submissão e rebeldia (2a ed.). São Paulo: Casa do Psicólogo.

Saviani, D. (2004). Perspectiva marxiana do problema subjetividadeintersubjetividade. Em N. Duarte (Org.), Crítica ao fetichismo da individualidade. Campinas, SP: Autores Associados.

Scalcon, S. (2002). À procura da unidade psicopedagógica. Articulando a pedagogia histórico-cultural com a pedagogia histórico-crítica. Campinas, SP: Autores Associados.

Schultz, D. (1975). História da psicologia moderna (2a ed.). São Paulo: Cultrix.

Tanamachi, E. R., \& Meira, M. E. M. (2003). A atuação do psicólogo como expressão do pensamento crítico em Psicologia e Educação. Em M. E. M. Meira, M. A. M. Antunes (Orgs.), Psicologia Escolar: práticas críticas (pp. 11-62). São Paulo: Casa do Psicólogo.

Tuleski, S. C. (2004). Reflexões sobre a gênese da Psicologia Científica. Em N. Duarte (Org.), Crítica ao fetichismo da individualidade. Campinas, SP: Autores Associados.

\section{Sobre a autora}

Karla Paulino Tonus (karla.psicologia@hotmail.com)

UNINOVE

Endereço: Rua Bartolomeu de Gusmão, 5-76 - CEP 17017-336, Jardim América, Bauru, SP

Este trabalho representa um segmento do $2^{\circ}$ capítulo da Tese intitulada "Psicologia e Educação - aproximação e apropriação", apresentada ao programa de Pós Graduação em Educação Escolar da Universidade Estadual Paulista, UNESP - campus Araraquara, como pré-requisito para a obtenção do título de doutor . 